\title{
The prognostic value of red cell distribution width (RDW), neutrophil-to-lymphocyte ratio (NLR), and platelet-to-lymphocyte ratio (PLR) in radiotherapy for oropharyngeal cancer
}

\author{
Emilia Staniewska ${ }^{1}$, Bartłomiej Tomasik ${ }^{2}$, Rafał Tarnawski ${ }^{1}$, Mateusz Łaszczych ${ }^{2}$, Marcin Miszczyk $^{1}$ \\ ${ }^{1}$ Maria Skłodowska-Curie National Research Institute of Oncology, Gliwice, Poland \\ ${ }^{2}$ Department of Biostatistics and Translational Medicine, Medical University of Łódź, Łódź, Poland
}

\begin{abstract}
Background: Red cell distribution width (RDW), neutrophil-to-lymphocyte ratio (NLR), and platelet-to-lymphocyte ratio (PLR) are known inflammatory indices. Elevated values are found in many cancers and may be associated with a poor prognosis. The article aimed to assess the impact of RDW, NLR, and PLR on overall survival (OS) of patients with oropharyngeal cancer treated with radiotherapy (RT).

Materials and methods: This retrospective study includes 208 patients treated for oropharyngeal cancer with definitive RT or RT combined with neoadjuvant or concurrent systemic therapy, at one institution between 2004 and 2014. The receiver operating characteristic (ROC) method, log-rank testing, and Cox proportional hazards regression model were used for the analysis. Results: The OS was significantly higher in RDW $\leq 13.8 \%(p=0.001)$ and NLR $\leq 2.099(p=0.016)$ groups. The RDW index was characterized by the highest discriminatory ability [area under the curve (AUC) $=0.59,95 \%$ confidence interval (CI): $0.51-0.67$ ], closely followed by NLR (AUC $=0.58,95 \% \mathrm{Cl}: 0.50-0.65$ ). In the univariate Cox regression analysis, RDW [hazard ratio (HR): 1.28 , 95\% Cl: 1.12-1.47, $\mathrm{p}<0.001$ ] and NLR (HR: 1.11,95\% Cl: 1.06-1.18, $\mathrm{p}<0.001$ ) were associated with an increased risk of death. In the multivariate analysis, among the analyzed indices, only NLR was significantly associated with survival (HR: $1.16,95 \% \mathrm{Cl}$ : $1.03-1.29, p=0.012$.

Conclusions: In the study, only NLR proved to be an independent predictor of OS. However, its clinical value is limited due to the relatively low sensitivity and specificity.

Key words: radiotherapy; oropharyngeal cancer; RDW; NLR; PLR

Rep Pract Oncol Radiother 2021;26(6):1010-1018
\end{abstract}

\section{Introduction}

Head and neck cancers (HNC) add up to nearly $5 \%$ of all registered cancers in Poland - about 7\% for males, and a little above $1 \%$ for females [1]. There were 1351 new cases of oropharyngeal cancer (ICD-10: C-01, C-05, C-09 and C-10 code) and
799 related deaths in 2016. The incidence presents an upward trend [2]. Risk factors for oropharyngeal cancer include male sex, the use of tobacco, alcohol, and oncogenic human papillomavirus (HPV) infection [3] which accounts for $10-70 \%$ of the cases, depending on the study [1]. HPV-associated cancer may occur at a younger age and has better

Address for correspondence: Emilia Staniewska, Maria Skłodowska-Curie National Research Institute of Oncology,

ul. Wybrzeża Armii Krajowej 15, 44-102 Gliwice, Poland; e-mail: em.staniewska@gmail.com

This article is available in open access under Creative Common Attribution-Non-Commercial-No Derivatives 4.0 International (CC BY-NC-ND 4.0) license, allowing to download articles and share them with others as long as they credit the authors and the publisher, but without permission to change them in any way or use them commercially 
survival rates compared to non-HPV-associated cancers [3].

Red blood cell distribution width (RDW) represents the variation in the red blood cell (RBC) volume. It is a simple, routinely performed laboratory test, which is useful in assessing the function of bone marrow, but can also be regarded as an inflammatory index [4]. Elevated RDW is associated with anemia, chronic inflammation, and malnutrition [5] which are frequently associated with advanced cancer [6]. Besides, chronic inflammation may further accelerate or lead to carcinogenesis and neovascularization due to inflammatory cytokines [7], and elevated RDW has proven to be a negative prognostic factor in many malignant tumors [8-12].

The neutrophil-to-lymphocyte ratio (NLR) is an index of circulating neutrophil and lymphocyte counts in the blood. The PLR means platelet-to-lymphocyte ratio and specifies the relation between platelet and lymphocyte counts circulating in the human body. Even though NLR and PLR are only conversions of routinely performed blood tests, they have shown to have a prognostic value in many non-oncological [13-15] and oncological diseases [16-18].

Because indices such as RDW, NLR, and PLR can be assessed using results of routinely performed blood tests, they could potentially be used as prog- nostic factors at no additional cost. The purpose of this study was to determine whether these indices are associated with survival in patients treated with radiotherapy (RT) due to the oropharyngeal cancer.

\section{Materials and methods}

\section{Study group}

The study is based on data from 208 patients treated for oropharyngeal cancer with definitive RT or RT in association with neoadjuvant or concurrent systemic therapy, including concomitant chemotherapy, immunotherapy, or both, at one institution between 2004 and 2014. Exclusion criteria included prior surgery and palliative intent of the treatment. Initially, the database consisted of 297 oropharyngeal cancer patients. Cases with unavailable blood test data $(82 ; 27.6 \%)$ or ongoing immunosuppressive treatment $(7 ; 2.4 \%)$ were removed from the analysis.

More than a half $(116 ; 55.8 \%)$ of the patients were treated with definitive RT, including conventional RT $(42 ; 36.2 \%)$, continuous accelerated irradiation (CAIR; 57; 49.1\%) [19], split-course accelerated hyperfractionated irradiation (CHA-CHA; $13 ; 11.2 \%$ ) [20], or external beam RT with brachytherapy boost (EBRT+BT; $2 ; 1.7 \%)$ or moderate hypofractionation $(2 ; 1.7 \%)$ (Tab. 1).

Table 1. Description of radiotherapy modalities

\begin{tabular}{|c|c|c|c|c|c|}
\hline Fractionation shedule & Description & $\begin{array}{l}\text { Number of } \\
\text { patients }\end{array}$ & $\begin{array}{c}\text { Complete } \\
\text { treatment time } \\
\text { (median, IQR) } \\
\text { [days] }\end{array}$ & $\begin{array}{c}\text { Total dose } \\
\text { (median, IQR) } \\
\text { [Gy] }\end{array}$ & $\begin{array}{c}\text { Fraction dose } \\
\text { (median, IQR) } \\
\text { [Gy] }\end{array}$ \\
\hline Conventional & $\begin{array}{c}\text { One fraction per day, } 5 \\
\text { days a week }\end{array}$ & 105 & $\begin{array}{c}50 \\
(48.0-52.0)\end{array}$ & $\begin{array}{c}70 \\
(70.0-72.0)\end{array}$ & $\begin{array}{c}2.0 \\
(2.0-2.0)\end{array}$ \\
\hline $\begin{array}{l}\text { Continuous accelerated } \\
\text { irradiation } \\
\text { (CAIR 1) }\end{array}$ & $\begin{array}{c}\text { One fraction per day, } 7 \\
\text { days a week }\end{array}$ & 76 & $\begin{array}{c}40 \\
(40.0-40.0)\end{array}$ & $\begin{array}{c}72 \\
(72.0-72.0)\end{array}$ & $\begin{array}{c}1.8 \\
(1.8-1.8)\end{array}$ \\
\hline $\begin{array}{l}\text { Continuous accelerated } \\
\text { irradiation } \\
\text { (CAIR 2) }\end{array}$ & $\begin{array}{c}\text { One fraction per day, } 7 \\
\text { days a week }\end{array}$ & 10 & $\begin{array}{c}41 \\
(41.0-41.0)\end{array}$ & $\begin{array}{c}68 \\
(68.0-68.0)\end{array}$ & $\begin{array}{c}1.7 \\
(1.7-1.7)\end{array}$ \\
\hline $\begin{array}{l}\text { Split-course accelerated } \\
\text { hyperfractionated irradiation } \\
(\mathrm{CHA}-\mathrm{CHA})\end{array}$ & $\begin{array}{l}\text { Two fractions a day, } \\
7 \text { days a week. } 8 \text { days } \\
\text { break midterm }\end{array}$ & 13 & $\begin{array}{c}28 \\
(28.0-28.0)\end{array}$ & $\begin{array}{c}64 \\
(64.0-64.0)\end{array}$ & $\begin{array}{c}1.6 \\
(1.6-1.6)\end{array}$ \\
\hline $\begin{array}{l}\text { External beam radiotherapy }+ \\
\text { brachytherapy boost } \\
(\text { EBRT+BT) }\end{array}$ & $\begin{array}{c}\text { One fraction per day, } \\
5 \text { or } 7 \text { days a week, } \\
\text { then BT }\end{array}$ & 2 & $\begin{array}{c}66 \\
(51.0-81.0)\end{array}$ & $\begin{array}{c}60+18 \\
(60.0-60.0)\end{array}$ & $\begin{array}{c}2.0+6 \\
(2.0-2.0)\end{array}$ \\
\hline Moderate hypofractionation & $\begin{array}{c}\text { One fraction per day, } 5 \\
\text { days a week }\end{array}$ & 2 & $\begin{array}{c}43 \\
(43.0-43.0)\end{array}$ & $\begin{array}{c}66 \\
(66.0-66.0)\end{array}$ & $\begin{array}{c}2.2 \\
(2.2-2.2)\end{array}$ \\
\hline
\end{tabular}

IQR — interquartile range; data presented as median value in applicable cases 
Patients treated with RT with concurrent systemic therapy $(47 ; 22.6 \%)$, received a sole-agent cisplatin (40;85.1\%), cisplatin with vinorelbine (3; $6.4 \%)$, or cisplatin with cetuximab $(1 ; 2.1 \%)$. Cetuximab was used as a sole agent in 2 cases $(4.3 \%)$ and panitumumab in one $(2.1 \%)$.

Twenty-three patients $(23 ; 11.1 \%)$ were treated with neoadjuvant chemotherapy in addition to concurrent systemic therapy, in which cisplatin was used as a sole agent in all of the cases $(23 ; 100 \%)$. Among the neoadjuvant chemotherapy regimens, cisplatin was used in association with Docetaxel and 5-Fluorouracil (5-FU) in 16 cases (69.6\%). Five patients $(5 ; 21.7 \%)$ received cisplatin with 5 -FU. One patient $(1 ; 4.3 \%)$ was treated with cisplatin with docetaxel and the last one $(1 ; 4.3 \%)$ - with cisplatin alone.

Twenty-two patients $(22 ; 10.6 \%)$ received only neoadjuvant chemotherapy. Likewise, cisplatin was used with docetaxel and 5-FU in 11 cases (50.0\%). Eight patients $(8 ; 36.4 \%)$ were treated with cisplatin and $5-\mathrm{FU}$, and 2 patients $(9.1 \%)$ - with cisplatin and docetaxel. In 1 case (4.5\%), cisplatin was a sole agent.

The majority of the tumors were squamous cell carcinomas $(200 ; 96.1 \%)$. Undifferentiated carcinoma was found in $6(6 ; 2.9 \%)$, and mucoepidermoid carcinoma in 2 cases $(2 ; 1.0 \%)$.

\section{Methodology}

The blood tests were performed within a month before the first fraction of RT in patients treated with definitive RT $(116 ; 55.8 \%)$ or RT with concurrent systemic therapy $(47 ; 22.6 \%)$ (Tab. 2), or before the first cycle of neoadjuvant chemotherapy
(45; 21.7\%). The median time from laboratory test to treatment was 2 days (interquartile range IQR $0-13$ ). All of the blood tests, including RDW, were performed at one laboratory and the derivative indices (NLR, PLR) were calculated retrospectively using the following formulas:

$$
\begin{aligned}
& \text { NLR }=\frac{[\text { neutrophil }]}{[\text { lymphocyte }]} \\
& P L R=\frac{[\text { platelet }]}{[\text { lymphocyte }]}
\end{aligned}
$$

The database included data regarding tobacco smoking, alcohol drinking history, and concomitant diseases. The TNM staging was evaluated using the American Joint Committee on Cancer $7^{\text {th }}$ Edition (2010) [21]. The HPV status data was not available, as it was not routinely assessed at our institution until 2017.

The follow-up was collected retrospectively from patients' medical history, the National Health Fund, and the Polish National Cancer Registry. Overall survival (OS) was defined as the time from the first fraction of RT in patients receiving definitive $\mathrm{RT}$ or concurrent systemic therapy $(163 ; 78.4 \%)$, or first cycle of neoadjuvant chemotherapy $(45 ; 21.6 \%)$, to the date of death. Dates of patients' death were available in all applicable cases. The remaining cases were censored using the last known date at which the patient was alive.

The study was performed retrospectively, based on available pre-existing data. The study protocol was approved by a Bioethical Committee (Maria Skłodowska-Curie National Research Institute of Oncology, Gliwice, Poland, KB/430-81/20).

Table 2. Comparison of the TNM stage of patients who received neoadjuvant chemotherapy, concurrent systemic therapy*

\begin{tabular}{|c|c|c|c|c|}
\hline & $\begin{array}{l}\text { Neoadjuvant Chemo- } \\
\text { radiotherapy } \\
(n=22)\end{array}$ & $\begin{array}{l}\text { Concurrent systemic } \\
\text { therapy* with radiotherapy } \\
(n=47)\end{array}$ & $\begin{array}{l}\text { Neoadjuvant chemotherapy } \\
\text { and concurrent systemic } \\
\text { therapy* with radiotherapy } \\
(n=23)\end{array}$ & $\begin{array}{l}\text { Definitive radiotherapy } \\
\qquad(n=116)\end{array}$ \\
\hline \multicolumn{5}{|c|}{ TNM stage [n(\%)] } \\
\hline I & & & & $6(5.2)$ \\
\hline II & & & & $19(16.4)$ \\
\hline III & $2(9.1)$ & $7(14.9)$ & $1(4.3)$ & $24(20.7)$ \\
\hline IV & $20(90.9)$ & $40(85.1)$ & $22(95.7)$ & $67(57.7)$ \\
\hline
\end{tabular}
or both of them, with radiotherapy and patients who did definitive radiotherapy

${ }^{*}$ Concurrent systemic therapy: concomitant chemotherapy or immunotherapy, or both 


\section{Statistical analysis}

The receiver operating characteristic (ROC) method, log-rank testing, and Cox proportional hazards regression model were used for the analysis.

Median OS (45.4 months) was chosen as a cut-off point for the ROC analysis. Cut-off values in the log-rank analysis were based on Youden index [22]. The univariate Cox analysis was performed using known clinical factors, which included: sex, age, TNM stage groups, primary tumor volume, nodal tumor volume, total tumor volume, history of smoking and pack-years, history of alcohol abuse (ICD-10: F-10 code; mental and behavioral disorders due to using alcohol), ZUBROD score, the addition of neoadjuvant chemotherapy or concurrent systemic therapy, and hematological indices: RDW, NLR and PLR.

All of the above variables were used as input for the backward stepwise selection model, using the threshold significance level for variable removal of
0.15 . For the variables remaining in the multivariate model, hazard ratios with $95 \%$ confidence intervals were reported. In the case of many significant interdependent variables, only the most statistically and clinically significant variables were included: GTV total instead of GTV primary and GTV nodal, and binary value for smoking status (smoker: no/yes) instead of number of pack-years.

The statistical analysis was performed using the STATISTICA 13.3 by TIBCO Software Inc.

\section{Results}

The median age in the study group was 58.8 (IQR: 54.1-65.9), and three-quarters of patients (156; 75.0\%) were male. At the time of treatment, 148 patients were active smokers (71.5\%), 22 ceased smoking within the last year (10.6\%) and 37 were non-smokers (17.9\%), who had stopped smoking at least one year before the treatment. The median pack-years was 30 (IQR: 15.0-35.0) (Tab. 3). Me-

Table 3. Baseline characteristics

\begin{tabular}{|c|c|c|c|c|}
\hline & \multicolumn{2}{|c|}{ RDW } & \multicolumn{2}{|c|}{ NLR } \\
\hline & Low ( $\leq 13.8 \%)$ & High (>13.8\%) & Low ( $\leq 2.099)$ & High (>2.099) \\
\hline & $n=120$ & $n=88$ & $n=90$ & $n=118$ \\
\hline Sex (\% of males) & 73.3 & 77.3 & 71.1 & 78.0 \\
\hline Age [years] & $\begin{array}{c}58.9 \\
(53.9-66.6)\end{array}$ & $\begin{array}{c}58.5 \\
(54.8-64.8)\end{array}$ & $\begin{array}{c}58.5 \\
(54.9-66.2)\end{array}$ & $\begin{array}{c}58.8 \\
(54.0-65.8)\end{array}$ \\
\hline RDW (\%) & $\begin{array}{c}12.9 \\
(12.6-13.4)\end{array}$ & $\begin{array}{c}14.6 \\
(14.2-15.0)\end{array}$ & $\begin{array}{c}13.5 \\
(12.9-14.5)\end{array}$ & $\begin{array}{c}13.7 \\
(12.9-14.3)\end{array}$ \\
\hline NLR & $\begin{array}{c}2.3 \\
(1.8-3.2)\end{array}$ & $\begin{array}{c}2.3 \\
(1.5-3.2)\end{array}$ & $\begin{array}{c}1.6 \\
(1.3-1.8)\end{array}$ & $\begin{array}{c}3.1 \\
(2.6-4.0)\end{array}$ \\
\hline PLR & $\begin{array}{c}131.3 \\
(99.0-176.9)\end{array}$ & $\begin{array}{c}122.0 \\
(98.1-167.0)\end{array}$ & $\begin{array}{c}102.8 \\
(83.8-126.5)\end{array}$ & $\begin{array}{c}166.4 \\
(119.4-201.4)\end{array}$ \\
\hline \multicolumn{5}{|l|}{ TNM stage (\%) } \\
\hline I & 2.5 & 3.4 & 4.4 & 1.7 \\
\hline$\|$ & 6.7 & 12.5 & 12.2 & 6.8 \\
\hline III & 17.5 & 14.8 & 20.0 & 13.6 \\
\hline IV & 73.3 & 69.3 & 63.3 & 78.0 \\
\hline $\mathrm{GTVp}\left[\mathrm{cm}^{3}\right]$ & $\begin{array}{c}20.4 \\
(13.4-31.3)\end{array}$ & $\begin{array}{c}24.3 \\
(14.2-40.7)\end{array}$ & $\begin{array}{c}17.6 \\
(10.5-24.6)\end{array}$ & $\begin{array}{c}28.3 \\
(16.4-43.6)\end{array}$ \\
\hline $\mathrm{GTVn}\left[\mathrm{cm}^{3}\right]$ & $\begin{array}{c}3.6 \\
(0.9-7.7)\end{array}$ & $\begin{array}{c}5.7 \\
(0.0-17.9)\end{array}$ & $\begin{array}{c}2.5 \\
(0.0-6.0)\end{array}$ & $\begin{array}{c}6.0 \\
(1.7-15.3)\end{array}$ \\
\hline GTVtotal $\left[\mathrm{cm}^{3}\right]$ & $\begin{array}{c}25.6 \\
(17.4-39.1)\end{array}$ & $\begin{array}{c}30.5 \\
(18.2-67.4)\end{array}$ & $\begin{array}{c}23.7 \\
(15.5-28.4)\end{array}$ & $\begin{array}{c}36.3 \\
(21.8-70.5)\end{array}$ \\
\hline Histopathology (\% SCC) & 96.7 & 95.5 & 95.6 & 96.6 \\
\hline
\end{tabular}


Table 3. Baseline characteristics

\begin{tabular}{|c|c|c|c|c|}
\hline & \multicolumn{2}{|c|}{ RDW } & \multicolumn{2}{|c|}{ NLR } \\
\hline & Low ( $\leq 13.8 \%)$ & High (>13.8\%) & Low ( $\leq 2.099)$ & High (>2.099) \\
\hline & $n=120$ & $n=88$ & $\mathrm{n}=90$ & $n=118$ \\
\hline \multicolumn{5}{|l|}{ History of smoking (\%) } \\
\hline Non-smoker & 22.7 & 11.4 & 20.2 & 16.1 \\
\hline Former smoker & 10.1 & 11.4 & 11.2 & 10.2 \\
\hline Active smoker & 67.2 & 77.3 & 68.5 & 73.7 \\
\hline Pack-years & $\begin{array}{c}25 \\
(10-35)\end{array}$ & $\begin{array}{c}30 \\
(20-40)\end{array}$ & $\begin{array}{c}25 \\
(10-35)\end{array}$ & $\begin{array}{c}30 \\
(20-35)\end{array}$ \\
\hline History of alcohol abuse* (\%) & 5.9 & 11.4 & 5.6 & 10.2 \\
\hline \multicolumn{5}{|l|}{ ZUBROD } \\
\hline 0 & 60.0 & 54.5 & 65.6 & 51.7 \\
\hline 1 & 38.3 & 39.8 & 33.3 & 43.2 \\
\hline 2 & 1.7 & 5.7 & 1.1 & 5.1 \\
\hline \multicolumn{5}{|l|}{ Fractionation regimen (\%) } \\
\hline Conventional & 55.0 & 40.9 & 47.8 & 50.0 \\
\hline Alternative & 45.0 & 59.1 & 52.2 & 50.0 \\
\hline $\begin{array}{l}\text { Addition of neoadjuvant } \\
\text { chemotherapy or concurrent } \\
\text { systemic therapy }{ }^{*}(\%)\end{array}$ & 55.0 & 29.5 & 42.2 & 45.8 \\
\hline \multicolumn{5}{|c|}{ Type of additional treatment (\%) } \\
\hline Neoadjuvant chemotherapy & 24.2 & 23.1 & 21.1 & 25.9 \\
\hline Concurrent systemic therapy ${ }^{* *}$ & 50.0 & 53.8 & 63.2 & 42.6 \\
\hline Both & 25.8 & 23.1 & 15.8 & 31.5 \\
\hline Median OS $=45.4$ months (\%) & 43.3 & 63.6 & 44.4 & 57.6 \\
\hline
\end{tabular}

RDW — red-cell distribution width; NLR — neutrophil-to-lymphocyte ratio; PLR — platelet-to-lymphocytes ratio; GTVp — primary tumor volume; GTVn — nodal tumor volume; GTVtotal — primary tumor volume (GTVp) and nodal tumor volume (GTVn); SCC — squamous cell carcinoma; OS — overall survival. "alcohol abuse (ICD-10: F-10 code): mental and behavioral disorders due to using alcohol; "concurrent systemic therapy: concomitant chemotherapy or immunotherapy, or both. Continuous variables are presented as median, and interquartile range (IQR) unless indicated otherwise. Dichotomous variables are presented as percentages

dian values of the RDW, NLR, and PLR were $13.6 \%$ (min-max range: $11.6-19.5 \%$; IQR: $12.9 \%-14.4 \%$ ), 2.3 (min-max range: $0.4-24.8$; IQR: $1.7-3.2$ ), and 128.8 (min-max range: 30.8-1150.0; IQR: 98.8-175.2), respectively.

Median OS was 45.4 months (IQR 15.59-87.18). The OS was significantly higher in patients with low RDW ( $\leq 13.8 \%$ and $>13.8 \%, \mathrm{p}=0.001)$ and low NLR ( $\leq 2.099$ and $>2.099, \mathrm{p}=0.016)$. Median OS for patients with RDW $\leq 13.8 \%$ was 55.3 months (95\% CI: 46.94-63.74) and 23.8 (95\% CI: 13.89-33.78) for those with RDW $>13.8 \%$ (Fig. 2). Similarly, median OS for patients with NLR $\leq 2.099$ was 60.4 months (95\% CI: 49.48-71.36), and 33.0 (95\% CI: 25.49-40.52) months for patients with NLR > 2.099 (Fig. 2).

The cut-off values were determined based on the results of ROC analysis (Fig. 1). The RDW index was characterized by the highest area under the curve, AUC (0.59, 95\% CI: 0.51-0.67, $\mathrm{p}=0.02)$, closely followed by the NLR $(0.58,95 \%$ CI: $0.50-0.65, \mathrm{p}=0.05)$. The PLR presented the lowest AUC (0.51, 95\% CI : 0.43-0.59, $\mathrm{p}=0.83$ ). The cut-off values for log-rank analysis were $13.8 \%$ for RDW (55.6\% sensitivity, $67.0 \%$ specificity) and 2.099 for NLR (63.9\% sensitivity, 50.0\% specificity). Due to the low AUC for PLR, it was not possible to discriminate a meaningful cut-off value, and therefore log-rank analysis was omitted.

The univariate Cox regression analysis showed that sex [hazard ratio (HR): 1.83, 95\% CI: 1.18-2.82, $\mathrm{p}=0.007$ ), history of smoking (HR: $1.74,95 \% \mathrm{CI}$ : $1.16-2.62, \mathrm{p}=0.008$ ), number of pack-years (HR: $1.01,95 \%$ CI 1.00-1.02, $\mathrm{p}=0.017)$, ZUBROD score (HR: 1.52, 95\% CI: $1.08-2.14, \mathrm{p}=0.017$ ), TNM stage (HR: $1.37,95 \% \mathrm{CI}: 0.93-2.03, \mathrm{p}=0.111$ ) 


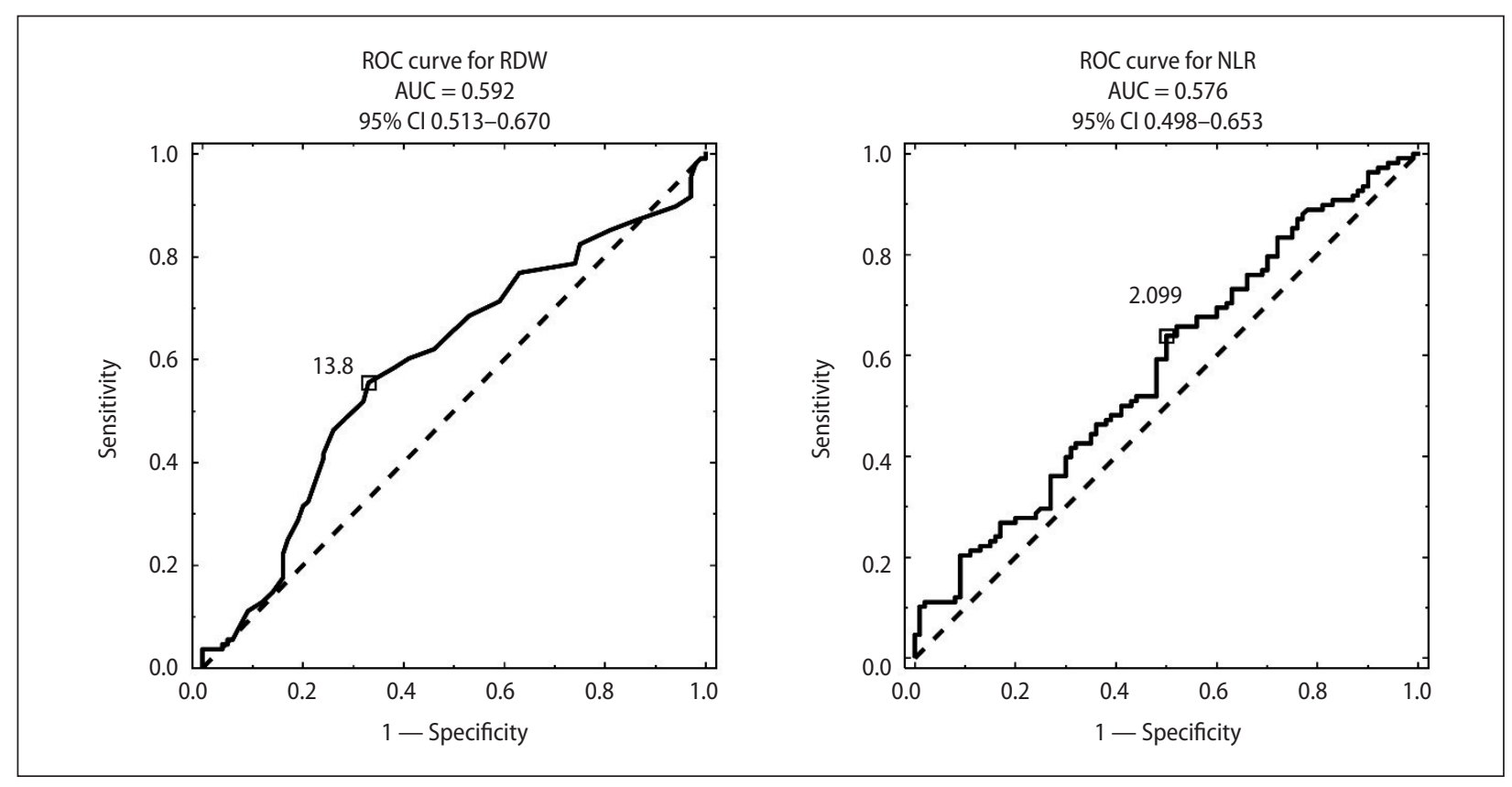

Figure 1. Receiver operating characteristic curve of red-cell distribution width and neutrophil-to-lymphocyte ratio for overall survival prediction

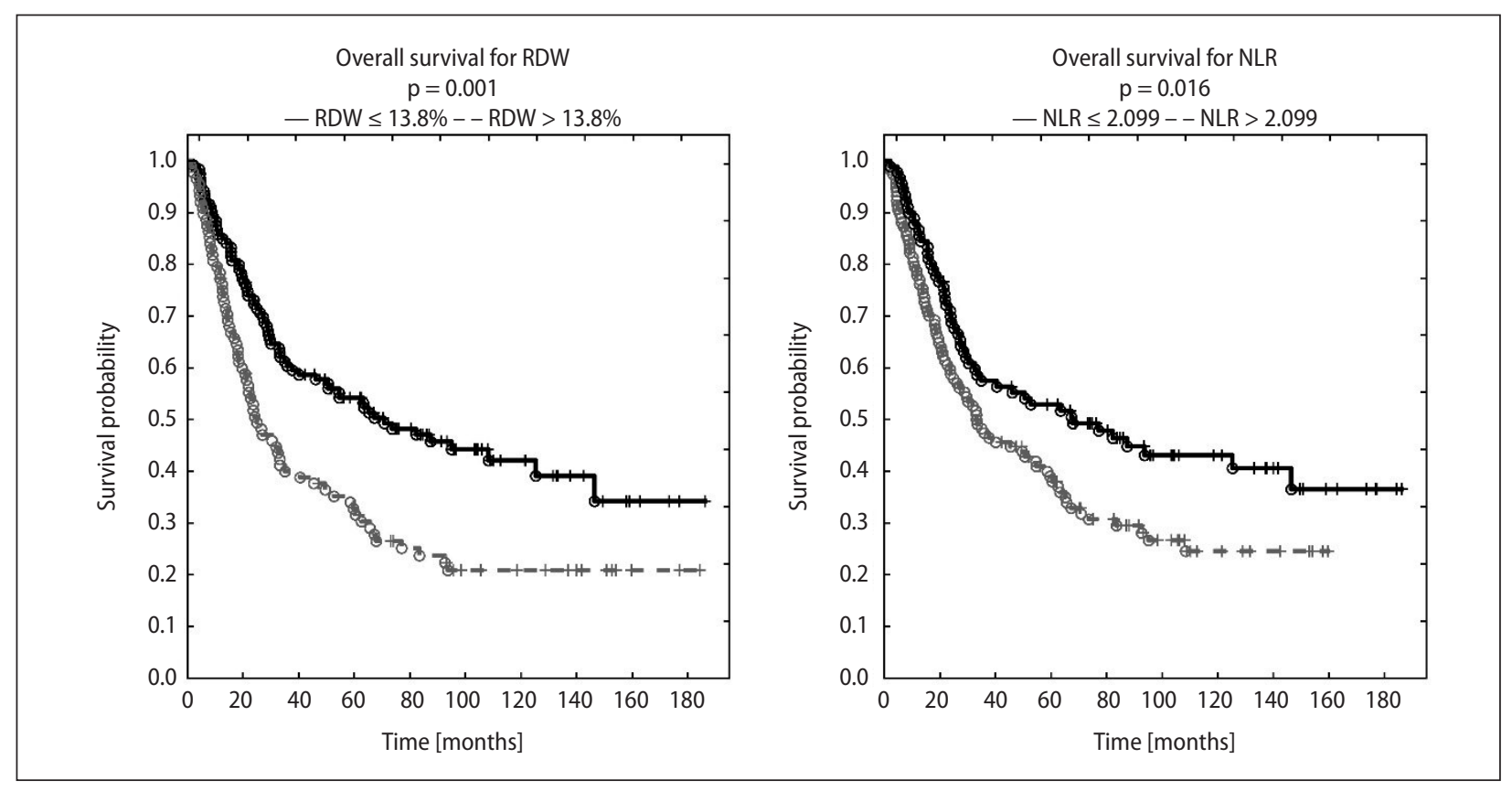

Figure 2. Kaplan-Meier curves for overall survival of patients with oropharyngeal cancer stratified by red-cell distribution width (RDW) and neutrophil-to-lymphocyte ratio (NLR) level

RDW (HR: 1.28, 95\% CI: 1.12-1.47, p < 0.001), NLR (HR: 1.11, 95\% CI: 1.06-1.18, p < 0.001), gross tumor volume (GTVp; HR: 1.12, 95\% CI: 1.03-1.21, $\mathrm{p}=0.005)$, nodal tumor volume (GTV n; HR: $1.12,95 \% \mathrm{CI}: 1.04-1.21, \mathrm{p}=0.002)$ and total tumor volume (GTV total; HR: 1.11, 95\%
CI: $1.05-1.16, \mathrm{p}<0.001)$ were associated with increased risk, while the addition of neoadjuvant chemotherapy or concurrent systemic therapy (HR: 0.54, 95\% CI: 0.38-0.78, $\mathrm{p}=0.001$ ) decreased the risk of death (Tab. 4). The hazard ratio indicates the change in the risk of death for every $10 \mathrm{~cm}^{3}$ of 
Table 4. Univariate and multivariate Cox Regression analysis of hazard ratio (HR) for overall survival (OS) in patients with oropharyngeal cancer

\begin{tabular}{|c|c|c|c|c|}
\hline \multirow[b]{2}{*}{ Covariates ${ }^{*}$} & \multicolumn{2}{|c|}{ Univariate analysis } & \multicolumn{2}{|c|}{ Multivariate analysis } \\
\hline & HR $(95 \% \mathrm{Cl})$ & p-value & HR $(95 \% \mathrm{Cl})$ & p-value \\
\hline Sex & $1.83(1.18-2.82)$ & 0.007 & & \\
\hline Age & $1.01(1.00-1.03)$ & 0.542 & $1.03(1.01-1.06)$ & 0.015 \\
\hline $\begin{array}{l}\text { History of smoking } \\
\text { (non-smokers vs. chain smokers) }\end{array}$ & $1.74(1.16-2.62)$ & 0.008 & $2.02(1.26-3.23)$ & 0.004 \\
\hline Pack-years & $1.01(1.00-1.02)$ & 0.017 & & \\
\hline History of alcohol abuse ${ }^{* *}$ & $1.24(0.63-2.45)$ & 0.528 & & \\
\hline ZUBROD (0 vs. 1, 2) & $1.52(1.08-2.14)$ & 0.017 & $2.02(0.96-4.26)$ & 0.064 \\
\hline $\begin{array}{l}\text { Addition of neoadjuvant chemotherapy } \\
\text { or concurrent systemic therapy }\end{array}$ & $0.54(0.38-0.78)$ & 0.001 & $0.58(0.38-0.90)$ & 0.013 \\
\hline TNM stage (1-3 vs. 4) & $1.37(0.93-2.03)$ & 0.111 & $1.91(1.21-3.02)$ & 0.005 \\
\hline $\mathrm{GTVp} \wedge\left[\mathrm{cm}^{3}\right]$ & $1.12(1.03-1.21)$ & 0.005 & & \\
\hline $\mathrm{GTV} \mathrm{n} \wedge\left[\mathrm{cm}^{3}\right]$ & $1.12(1.04-1.21)$ & 0.002 & & \\
\hline GTV total^ $\left[\mathrm{cm}^{3}\right]$ & $1.11(1.05-1.16)$ & $<0.001$ & $1.10(1.03-1.17)$ & 0.002 \\
\hline RDW & $1.28(1.12-1.47)$ & $<0.001$ & $1.13(0.97-1.32)$ & 0.118 \\
\hline NLR & $1.11(1.06-1.18)$ & $<0.001$ & $1.16(1.03-1.29)$ & 0.012 \\
\hline PLR & $1.01(1.00-1.03)$ & 0.091 & $0.997(0.995-0.999)$ & 0.026 \\
\hline
\end{tabular}

RDW - red-cell distribution width; NLR — neutrophil-to-lymphocyte ratio; PLR — platelet-to-lymphocytes ratio; GTVp — primary tumor volume; GTVn - nodal tumor volume; GTVtotal — primary tumor volume (GTVp) and nodal tumor volume (GTVn); Cl — confidence interval; "all of the variables included in univariate analysis were used as input for the backward stepwise selection model, using the threshold significance level for variable removal of 0.15 . For the variables remaining in the multivariate model, hazard ratios with $95 \% \mathrm{Cl}$ were reported; " alcohol abuse (ICD-10: F-10 code): mental and behavioral disorders due to using alcohol; ^per increase by $10 \mathrm{~cm}^{3}$

gross tumor volume (GTVp), nodal (GTVn) and total tumor volume (GTVtotal).

In the multivariate analysis, history of smoking (HR: $1.03,95 \%$ CI: $1.26-3.23, \mathrm{p}=0.004$ ), the addition of neoadjuvant chemotherapy or concurrent systemic therapy (HR: $0.58,95 \%$ CI: $0.38-0.90$, $\mathrm{p}=0.013$ ), total GTV (HR: 1.10, 95\% CI: 1.03-1.17, $\mathrm{p}=0.002)$, age (HR: 1.03, 95\% CI: 1.01-1.06, $\mathrm{p}=0.015$ ), and NLR (HR: 1.16, 95\% CI: 1.03-1.29, $\mathrm{p}=0.012)$ remained as cofactors significantly associated with OS (Tab. 4).

Due to the lack of statistical significance in univariate analysis, low values of the hazard ratio and 95\% confidence interval (HR: 0.997, 95\% CI: 0.995-0.999), and the relatively high p-value $(\mathrm{p}=0.026)$ in multivariate models, PLR was presumed to be a clinically insignificant factor.

\section{Discussion}

Beyond the usual clinical applications, both RDW, NLR, and PLR have been a subject of investigation in oncology and proven to be useful as prognostic factors in many cancers. For example, some studies have proved the connection of the RDW with prognosis in head and neck cancer [12], digestive tract including esophagus [8], colon and rectum [9], or gastric cancer [10]. The elevated value of RDW was associated with poor survival in breast cancer patients [11]. Preoperative RDW and NLR high levels were found to be independent predictors of worse survival in gliomas [23].

In this study, the median OS was significantly higher in patients with lower RDW and NLR. However, an association between the PLR and OS was not found. There are mixed reports in the literature concerning RDW, NLR, and survival in head and neck cancer patients. Moreover, the cut-off values are significantly different. For example, in the aforementioned studies, the authors used the cut-off values of $13.2 \%$ [24] and 15\% [25] for RDW, and 2.32 [26], 2.2 [27], 1.81 [28] and 3.9 [29] for NLR.

Although there are some reports which suggest that PLR might be associated with survival in head and neck cancers [26, 27], other studies confirm our finding that it is not a significant factor for OS [28-30].

Ye et al. performed a study on 427 patients with nasopharyngeal carcinoma receiving definitive RT. The authors showed that high values of pre-treat- 
ment NLR and PLR were associated with worse OS [26]. Preoperative high NLR and PLR were found to be significant factors of poor OS in a retrospective study focused on postoperative laryngeal cancer, conducted by Xun et al., but no significant impact of RDW on OS was found [27]. Bojaxhiu et al. analyzed 186 patients retrospectively with various locations of HNC and treated with (chemo-) radiation. Results of the study showed that elevated values of pre-treatment NLR were associated with shorter OS, while PLR was not [28]. According to Young et al., pre-treatment NLR is an independent factor for locoregional control but, just like PLR, does not influence the OS [30]. Ge et al. found that high pre-operative RDW is an independent factor of poor OS in patients with squamous cell carcinoma of the oral cavity treated with surgery [25]. Hsueh et al. described the negative correlation between elevated values of RDW and OS, based on a large cohort study of 809 male laryngeal squamous cell carcinoma patients [24]. Szilasi et al. showed in their study that high values of NLR affect the OS in patients with various locations of head and neck cancers [29].

The major limitation of this study is the lack of knowledge on the HPV status for oropharyngeal cancer patients. Generally, HPV-related oropharyngeal cancers are associated with better survival compared to non-HPV cancers [3], and the inclusion of this prognostic factor could have significantly altered the outcome of the multivariate analysis. However, since the routine HPV testing was introduced in 2017, the length of the follow-up and quantity of patients with such data available at our institution are by far insufficient.

It should be noted that treatment methods in this study were not homogeneous. Patients were treated by definitive RT or RT with neoadjuvant chemotherapy or concurrent systemic therapy, including concomitant chemotherapy and immunotherapy. Different RT regimens were also applied. In connection with the above, the relatively high heterogeneity and comparatively small number of patients (208) are other limitations of this article.

Besides, the study was performed retrospectively and, therefore, challenged by the biases of retrospective data collection.

Among hematological indices analyzed in the study, only NLR was a statistically significant predictor in multivariate models. The lack of statistical significance of the remaining indices, in this and other articles, is due to some important reasons. The cut-off values differed between cited authors and were often determined by other statistical methods. What is more, values of RDW, NLR, and PLR are connected with concomitant diseases' burden or past medical history, which are very diversified among the patients. These factors affect the level of inflammation that directly impacts the analyzed hematological indices.

Despite the considerable interest of many authors in RDW, NLR, and PLR indeces, there is limited data regarding their usefulness in clinical daily practice. Our analysis showed that only NLR is an independent prognostic factor. Considering the above, and relatively low specificity and sensitivity of both RDW and NLR in the ROC analysis, despite significant differences between groups in univariate survival analysis, it is advisable to use these indices in practice with caution.

\section{Conclusions}

In the study, only NLR proved to be an independent predictor of OS. However, its clinical value is limited due to the relatively low sensitivity and specificity.

None declared.

\section{Conflicts of interest}

\section{Funding}

The authors did not receive any substantial funding for the preparation of this manuscript.

None declared.

\section{Acknowledgements}

\section{References}

1. Kawecki A., Nawrocki S. (ed). Nowotwory nabłonkowe narządów głowy i szyi . http://onkologia.zalecenia.med. pl/pdf/zalecenia_PTOK_tom1_01_Nowotwory_nablonkowe_glowy_i_szyi_20140807.pdf.

2. Wojciechowska U, Czaderny K, Ciuba A, et al. Cancer in Poland - 2016. http://onkologia.org.pl/wp-content/ uploads/Nowotwory_2016.pdf (2018).

3. Hansen EK, Roach M. Handbook of evidence-based radiation oncology. Springer Science, New Yor 2018: 1-969.

4. Salvagno GL, Sanchis-Gomar F, Picanza A, et al. Red blood cell distribution width: A simple parameter with multiple clinical applications. Crit Rev Clin Lab Sci. 2015; 52(2): 86-105, doi: 10.3109/10408363.2014.992064, indexed in Pubmed: 25535770. 
5. Lippi G, Plebani M. Red blood cell distribution width (RDW) and human pathology. One size fits all. Clin Chem Lab Med. 2014; 52(9): 1247-1249, doi: 10.1515/cclm-20140585, indexed in Pubmed: 24945432.

6. Argilés JM. Cancer-associated malnutrition. Eur J Oncol Nurs. 2005; 9 Suppl 2: S39-S50, doi: 10.1016/j. ejon.2005.09.006, indexed in Pubmed: 16437757.

7. Montagnana $M$, Danese E. Red cell distribution width and cancer. Ann Transl Med. 2016; 4(20): 399, doi: 10.21037/ atm.2016.10.50, indexed in Pubmed: 27867951.

8. Xu WY, Yang XB, Wang WQ, et al. Prognostic impact of the red cell distribution width in esophageal cancer patients: A systematic review and meta-analysis. World J Gastroenterol. 2018; 24(19): 2120-2129, doi: 10.3748/wjg.v24. i19.2120, indexed in Pubmed: 29785080.

9. Pedrazzani $C$, Tripepi M, Turri G, et al. Prognostic value of red cell distribution width (RDW) in colorectal cancer. Results from a single-center cohort on 591 patients. Sci Rep. 2020; 10(1): 1072, doi: 10.1038/s41598-020-57721-4, indexed in Pubmed: 31974409.

10. Yazici P, Demir U, Bozkurt E, et al. The role of red cell distribution width in the prognosis of patients with gastric cancer. Cancer Biomarkers. 2017; 18(1): 19-25, doi: 10.3233/ CBM-160668, indexed in Pubmed: 27814271.

11. Huang DP, Ma RM, Xiang YQ. Utility of Red Cell Distribution Width as a Prognostic Factor in Young Breast Cancer Patients. Medicine (Baltimore). 2016; 95(17): e3430, doi: 10.1097/MD.0000000000003430, indexed in Pubmed: 27124030.

12. Miszczyk M, Jabłońska I, Magrowski $\measuredangle$, et al. The association between RDW and survival of patients with squamous cell carcinoma of the tongue. Simple, cheap and convenient? Rep Pract Oncol Radiother. 2020; 25(4): 494-499, doi: 10.1016/j.rpor.2020.03.026, indexed in Pubmed: 32477015.

13. Wang Q, Ma J, Jiang Z, et al. Prognostic value of neutrophilto-lymphocyte ratio and platelet-to-lymphocyte ratio in acute pulmonary embolism: a systematic review and meta-analysis. Int Angiol. 2018; 37(1): 4-11, doi: 10.23736/ S0392-9590.17.03848-2, indexed in Pubmed: 28541022.

14. Gasparyan AY, Ayvazyan L, Mukanova U, et al. The Platelet-to-Lymphocyte Ratio as an Inflammatory Marker in Rheumatic Diseases. Ann Lab Med. 2019; 39(4): 345-357, doi: 10.3343/alm.2019.39.4.345, indexed in Pubmed: 30809980.

15. Liu CC, Ko HJ, Liu WS, et al. Neutrophil-to-lymphocyte ratio as a predictive marker of metabolic syndrome. Medicine (Baltimore). 2019; 98(43): e17537, doi: 10.1097/MD.0000000000017537, indexed in Pubmed: 31651856.

16. Diem S, Schmid S, Krapf M, et al. Neutrophil-to-Lymphocyte ratio (NLR) and Platelet-to-Lymphocyte ratio (PLR) as prognostic markers in patients with non-small cell lung cancer (NSCLC) treated with nivolumab. Lung Cancer. 2017; 111: 176-181, doi: 10.1016/j.lungcan.2017.07.024, indexed in Pubmed: 28838390.

17. Prabawa IP, Bhargah A, Liwang F, et al. Pretreatment Neutrophil-to-Lymphocyte ratio (NLR) and Platelet-toLymphocyte Ratio (PLR) as a Predictive Value of Hematological Markers in Cervical Cancer. Asian Pac J Cancer Prev. 2019; 20(3): 863-868, doi: 10.31557/APJCP.2019.20.3.863, indexed in Pubmed: 30912405.
18. Sun Y, Zhang L. The clinical use of pretreatment NLR, $P L R$, and LMR in patients with esophageal squamous cell carcinoma: evidence from a meta-analysis. Cancer Manag Res. 2018; 10: 6167-6179, doi: 10.2147/CMAR.S171035, indexed in Pubmed: 30538564.

19. Skladowski K, Maciejewski B, Golen M, et al. Continuous accelerated 7-days-a-week radiotherapy for head-and-neck cancer: long-term results of phase III clinical trial. Int J Radiat Oncol Biol Phys. 2006; 66(3): 706-713, doi: 10.1016/j. ijrobp.2006.05.026, indexed in Pubmed: 17011446.

20. Miszczyk L, Maciejewski B, Tukiendorf A, et al. Split-course accelerated hyperfractionated irradiation ( $\mathrm{CHA}-\mathrm{CHA})$ as a sole treatment for advanced head and neck cancer patients-final results of a randomized clinical trial. $\mathrm{Br} \mathrm{J} \mathrm{Ra}$ diol. 2014; 87(1041):20140212, doi: 10.1259/bjr.20140212, indexed in Pubmed: 25027170.

21. Edge SB. AJCC Cancer Staging Manual 7th Edition. 7th ed. Springer International Publishing, London 2010.

22. Youden WJ. Index for rating diagnostic tests. Cancer. 1950; 3(1): 32-35, doi: 10.1002/1097-0142(1950)3:1<32::aidcncr2820030106>3.0.co;2-3, indexed in Pubmed: 15405679.

23. Wang DP, Kang K, Lin Qi, et al. Prognostic Significance of Preoperative Systemic Cellular Inflammatory Markers in Gliomas: A Systematic Review and Meta-Analysis. Clin Transl Sci. 2020; 13(1): 179-188, doi: 10.1111/cts.12700, indexed in Pubmed: 31550075.

24. Hsueh CY, Lau HC, Li S, et al. Pretreatment level of red cell distribution width as a prognostic indicator for survival in a large cohort study of male laryngeal squamous carcinoma. Frontiers in Oncology; 9. Epub ahead of print 2019. Front Oncol. 2019; 9: 271, doi: 10.3389/fonc.2019.00271, indexed in Pubmed: 3104119.

25. Ge W, Xie J, Chang L. Elevated red blood cell distribution width predicts poor prognosis in patients with oral squamous cell carcinoma. Cancer Manag Res. 2018; 10: 3611-3618, doi: 10.2147/CMAR.S176200, indexed in Pubmed: 30271209.

26. Ye L, Oei RW, Kong F, et al. Prognostic values of hematological biomarkers in nasopharyngeal carcinoma patients treated with intensity-modulated radiotherapy. Eur Arch Otorhinolaryngol. 2018; 275(5): 1309-1317, doi: 10.1007/ s00405-018-4956-X, indexed in Pubmed: 29589142.

27. Xun $Y$, Wang $M$, Sun $H$, et al. Prognostic Analysis of Preoperative Inflammatory Biomarkers in Patients With Laryngeal Squamous Cell Carcinoma. Ear Nose Throat J. 2020; 99(6): 371-378, doi: 10.1177/0145561319876910, indexed in Pubmed: 31569972.

28. Bojaxhiu B, Templeton AJ, Elicin O, et al. Relation of baseline neutrophil-to-lymphocyte ratio to survival and toxicity in head and neck cancer patients treated with (chemo-) radiation. Radiat Oncol. 2018; 13(1): 216, doi: 10.1186/ s13014-018-1159-y, indexed in Pubmed: 30400969.

29. Szilasi Z, Jósa V, Zrubka Z, et al. Neutrophil-To-Lymphocyte and Platelet-To-Lymphocyte Ratios as Prognostic Markers of Survival in Patients with Head and Neck Tumours-Results of a Retrospective Multicentric Study. Int J Environ Res Public Health. 2020; 17(5), doi: 10.3390/ ijerph17051742, indexed in Pubmed: 32155982.

30. Young CA, Murray LJ, Karakaya E, et al. The Prognostic Role of the Neutrophil-to-Lymphocyte Ratio in Oropharyngeal Carcinoma Treated with Chemoradiotherapy. Clin Med Insights Oncol. 2014; 8: 81-86, doi: 10.4137/CMO.S15476, indexed in Pubmed: 25057245. 